\title{
Seasonal effects on the response of ovarian follicles to IGF1 in mares
}

\author{
L K Doyle, C O Hogg, E D Watson and F X Donadeu \\ The Roslin Institute and Royal (Dick) School of Veterinary Studies, Roslin BioCentre, University of Edinburgh, \\ Midlothian EH25 9PS, UK \\ Correspondence should be addressed to FX Donadeu; Email: xavier.donadeu@ed.ac.uk
}

\begin{abstract}
The response of follicles to IGF1 was compared between the transition into the ovulatory season (transitional period) and the ovulatory season (ovulatory period) in eight mares using a cross-over experimental design within periods. Granulosa cells were collected from follicles 15-24 or 25-34 mm and expression of IGF1R, IGF2R, FSHR, LHCGR and PAPPA was determined by qPCR. In addition, $10 \mathrm{mg}$ IGF1 or vehicle were injected into the largest follicle (transitional period) or the second largest follicle (ovulatory period) of a follicular wave before the beginning of diameter deviation between the two largest follicles (mean diameters at injection 19.2 and $20.0 \mathrm{~mm}$ during transitional and ovulatory periods respectively). Follicular fluid was collected $24 \mathrm{~h}$ after injection for determination of free IGF1, IGFBP, inhibin A and oestradiol levels. Granulosa cells from follicles $25-34 \mathrm{~mm}$, but not follicles 15-24 mm, expressed higher levels of IGF1R $(P=0.01), F S H R(P<0.007)$ and LHCGR $(P=0.09)$ during the ovulatory period than during the transitional period, whereas IGF2R expression was higher in transitional than ovulatory follicles $(P=0.06)$. Follicular IGFBP2 levels were not different $(P>0.1)$ between periods and treatments, whereas IGFBP5 levels were higher $(\boldsymbol{P}<0.05)$ during the ovulatory period. Finally, IGF1 injection before the beginning of deviation induced an approximately twofold increase $(P=0.01)$ in follicular inhibin A levels during each period and did not affect oestradiol $(P>0.1)$. These results suggest that, as during ovulatory waves, equine follicles during transitional waves are responsive to IGF1 before the beginning of deviation and that, therefore, inadequate IGF1 responsiveness before deviation may not underlie the deficient development of dominant follicles during transition.
\end{abstract}

Reproduction (2008) 136 589-598

\section{Introduction}

The period of spring transition between the anovulatory season and the ovulatory season in the mare is characterised by renewed follicular growth (reviewed in Donadeu \& Watson 2007). During this period, follicular waves occur that can sequentially produce several large, anovulatory follicles usually in association with irregular periods of oestrus. This makes reproductive management of these mares difficult as it is virtually impossible to predict with accuracy when ovulation will occur.

Similar to follicular waves during the ovulatory season, waves during transition are characterised by a deviation in diameter between the largest follicle and smaller follicles when the largest follicle reaches about $23 \mathrm{~mm}$ (Donadeu \& Ginther 2004). The largest follicle thus continues growing and becomes dominant whereas smaller follicles (subordinate follicles) cease growing and regress. However, although transitional dominant follicles can reach final diameters similar to their ovulatory counterparts, they have an underdeveloped theca, are poorly vascularised, express low levels of receptors for luteinising hormone (LHCGR) and have reduced capacity to produce steroids (Watson \& Al-zi'abi 2002, Acosta et al. 2004, Watson et al. 2004b). These features critically determine the anovulatory fate of these follicles. For example, adequate vascularisation as well as high intrafollicular levels of oestrogen and other growth factors enhance follicular responsiveness to gonadotrophins, and this is essential to meet the increased trophic demands for the development of ovulatory-competent follicles (Ginther et al. 2003). In addition, an increase in the ability of dominant follicles to produce oestrogen at the end of the spring transition is believed to be critical for the occurrence of the $\mathrm{LH}$ surge that triggers the onset of the ovulatory season (Sharp et al. 1991, 2001).

The reasons for the morphological, biochemical and functional deficiencies of dominant follicles during the transitional period are not clear. Low circulating $\mathrm{LH}$ levels and low follicular expression of $\mathrm{LH}$ receptor likely play a role (Donadeu \& Ginther 2002a, Watson et al. 2004b). In addition, follicular responsiveness to circulating follicle-stimulating hormone ( $\mathrm{FSH}$ ) may be altered during the anovulatory season (Donadeu \& Ginther 2002a, 2003, King et al. 2008), although seasonal 
changes in $\mathrm{FSH}$ receptor ( $F S H R$ ) expression in follicles have not been determined. Another trophic factor that is likely involved is insulin-like growth factor 1 (IGF1). In ovulatory mares, IGF1 availability increases specifically in the dominant follicle before the beginning of diameter deviation (Donadeu \& Ginther 2002 b, Spicer et al. 2005) where IGF1 binds to IGF receptor type 1 (IGF1R) to amplify the effects of gonadotrophins on follicular cell proliferation and steroid production, among other functions (Glister et al. 2001). Expression of IGF1R has been reported to change during antral follicle growth in sheep (Perks et al. 1995) whereas changes in IGF1R have been reported in theca cells but not granulosa cells during growth of bovine follicles (Stewart et al. 1996, Armstrong et al. 2000, Llewellyn et al. 2007). In addition to IGF1, IGF2 is found in equine follicular fluid (Bridges et al. 2002) and can bind and activate IGF1R (Spicer \& Aad 2007). IGF2 activity is negatively regulated by IGF2 binding to a second receptor, IGF2R (Delaine et al. 2007). Follicular availability of IGF1 is thought to be regulated primarily by IGF-binding proteins (IGFBPs) which render IGF1 inactive (Mazerbourg et al. 2003). In ovulatory mares, levels of IGFBPs, most notably IGFBP2 and IGFBP5, decrease in the dominant follicle and this is attributable, at least in part, to the proteolytic activity of pregnancy-associated plasma protein-A (PAPPA, Gerard \& Monget 1998, Gerard et al. 2004).

The decisive role of IGF1 in follicle selection and the development of ovulatory follicles in mares has been demonstrated in a series of studies by Ginther and associates who showed that injection of IGF1 into the second largest follicle of a wave at the beginning of deviation resulted in the follicle becoming dominant, rather than naturally subordinate, and eventually ovulating (Ginther et al. 2004b, 2004c), whereas intrafollicular injection of IGFBP3 blocked the development of the future dominant follicle (Ginther et al. 2004a). These responses were associated with specific changes in levels of inhibin A and other growth factors in response to intrafollicular injection of IGF1 or IGFBP3.

In relation to seasonally anovulatory mares, Acosta et al. (2004) reported lower concentrations of free IGF1 (not bound to IGFBPs) in large transitional follicles than in ovulatory follicles and Watson et al. (2004a) demonstrated that the large transitional follicles had higher levels of IGFBP2. Taken, together, these findings strongly suggest that dominant follicles during transition grow in an IGF1-deficient environment that determines the anovulatory status of transitional mares. Therefore, artificially increasing IGF1 early during the development of a dominant follicle (i.e. before it begins to deviate in diameter from smaller follicles) may be potentially used to facilitate ovulation during transition, as has been reported during the ovulatory season (Ginther et al. $2004 b, 2004 c)$. Such approach would only be effective if these follicles maintained their response to IGF1 during the transitional period.
The objective of this study was to investigate seasonal changes in follicular responsiveness to IGF1 in mares by testing the hypothesis that the response to intrafollicular injection of IGF1 before the beginning of diameter deviation would be similar during transitional and ovulatory periods. This was done by determining during these two periods 1) granulosa cell expression of IGF1R as well as other genes that may have an effect on the responsiveness of cells to IGF1, namely, IGF2R, FSHR, LHCGR and PAPPA, 2) follicular levels of IGFBP2 and IGFBP5 and 3) changes in follicular inhibin $A$ and oestradiol levels after an intrafollicular injection of IGF1. In testing the hypothesis, a novel experimental approach was applied using the second largest follicle of an ovulatory wave as a model to study the responses of transitional follicles to injection of IGF1. The rationale for this was based on 1) the common anovulatory nature of these two types of follicles which is derived, at least in part, from their development in a IGF1-deficient environment and 2) the well-established biochemical and functional responses of the second largest follicle of an ovulatory wave to IGF1 injection (Ginther et al. 2004c, 2005).

\section{Results}

The first ovulation of the year occurred between 11 April and 24 May (median date, 29 April) which coincides with the expected onset of the ovulatory season in this latitude (Watson et al. 2004a).

\section{Gene expression in granulosa cells}

Granulosa cell pellets for gene expression analyses were obtained from a total of 12 follicle ablation sessions during the transitional period and 14 sessions during the ovulatory period. Between 4 and 7 pools (one to four follicles per pool) were obtained within the 15-24 and 25-34 mm categories during each period. Mean diameter of follicles included in a pool during transitional and ovulatory periods were $19.2 \pm 2.0$ and $16.9 \pm 1.0 \mathrm{~mm}$ respectively for the $15-24 \mathrm{~mm}$ category, and $29.7 \pm 0.3$ and $31.7 \pm 1.1 \mathrm{~mm}$ for the $25-34 \mathrm{~mm}$ category. Mean diameters were not different $(P>0.1)$ between periods within each category.

Results of qPCR analyses are shown in Fig. 1. Although there were no main effects $(P>0.4)$ of period or follicle size for IGF1R expression, there was a significant $(P=0.03)$ interaction due to sixfold higher $(P=0.01)$ mean levels of IGF1R mRNA in $25-34 \mathrm{~mm}$ follicles during the ovulatory period than during the transitional period but no differences $(P>0.5)$ between $15-24 \mathrm{~mm}$ follicles during the two periods. Analysis within period indicated that during the ovulatory period $25-34 \mathrm{~mm}$ follicles had greater $(P=0.04)$ IGF1R mRNA levels than $15-24 \mathrm{~mm}$ follicles. Although there was no effect of 

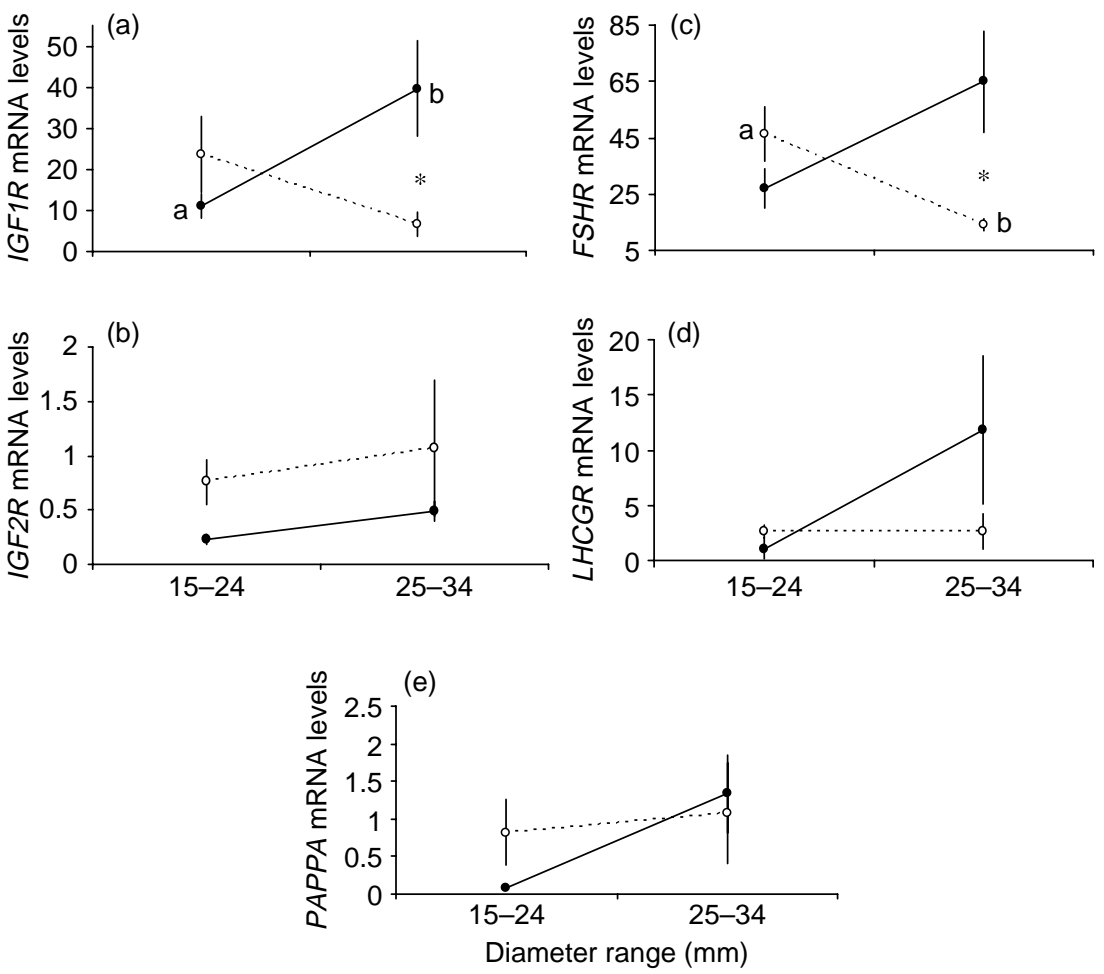

follicle size or an interaction $(P>0.2)$ for IGF2R expression, the effect of period tended to be significant $(P=0.06)$, with higher mean expression levels during the transitional period than during the ovulatory period. As for IGF1R, there were no main effects $(P>0.2)$ of period or follicle size for FSHR expression but there was an interaction $(P=0.007)$ which was due to higher levels (approximately fivefold) in $25-34 \mathrm{~mm}$ follicles during the ovulatory period than during the transitional period. In addition, during the transitional period, 15-24 mm follicles had greater $(P=0.024)$ levels of FSHR mRNA than 25-34 mm follicles. For LHCGR expression, the interaction between period and follicle size approached significance $(P=0.09)$ due to higher mean expression in 25-34 mm follicles during the ovulatory period than during the transitional period. There were no overall main effects or an interaction $(P>0.2)$ for PAPPA expression; however, analysis of expression levels within the ovulatory period indicated a tendency $(P=0.08)$ for higher PAPPA mRNA levels in 25-34 than 15-24 mm follicles.

\section{Follicular responses to IGF1}

Data from a total of seven mares were removed from the analyses after follicular injections for the following reasons; target follicle could not be identified with total certainty (three mares), failed intrafollicular injection (one mare), follicle collapsed after injection with vehicle (one mare) and follicular fluid was grossly contaminated with blood (two mares). As a result, data from five to seven mares were available for analyses within each treatment and period.

Diameters of target follicles on the day of injection were not affected by period $(P>0.1)$ and were similar $(P>0.1)$ between vehicle- and IGF1-treated mares during the transitional period (largest follicle, $19.2 \pm 0.3$ and $19.1 \pm 0.5 \mathrm{~mm}$ respectively) and the ovulatory period (second largest follicle, $20.4 \pm 1.2$ and $19.8 \pm 0.3 \mathrm{~mm}$ ). Changes in diameter during the first $24 \mathrm{~h}$ after injection of vehicle or IGF1 were $0.6 \pm 1.3$ and $-0.3 \pm 1.4 \mathrm{~mm}$ respectively for the largest follicle during the transitional period, and $-2.0 \pm 2.1$ and $-1.6 \pm 1.5 \mathrm{~mm}$ for the second largest follicle during the ovulatory period. These changes were not affected $(P>0.1)$ by period, treatment or their interaction.

As expected, free IGF1 concentrations in follicular fluid (Fig. 2a) increased after IGF1 injection (main effect of treatment, $P=0.01$ ) but were not affected by period or the interaction of treatment $\times$ period $(P>0.1)$. Determination of relative IGFBP2 and IGFBP5 levels in follicular fluid by immunoblotting revealed bands that were 32-36 kDa (Fig. 2b) and 25-29 kDa (Fig. 2c) respectively, which is consistent with previous reports using western ligand blotting in equine follicular fluid (Gerard \& Monget 1998, Bridges et al. 2002, Watson et al. 2004a). Follicular IGFBP2 levels were not affected $(P>0.1)$ by period, treatment or period $\times$ treatment but this interaction was significant $(P<0.03)$ for levels of IGFBP5 due to higher levels in vehicle-treated mares 


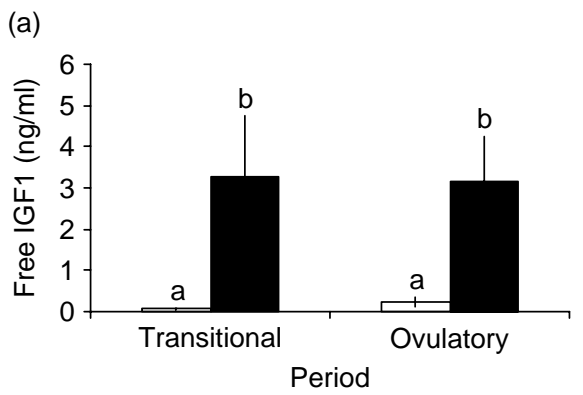

(b)
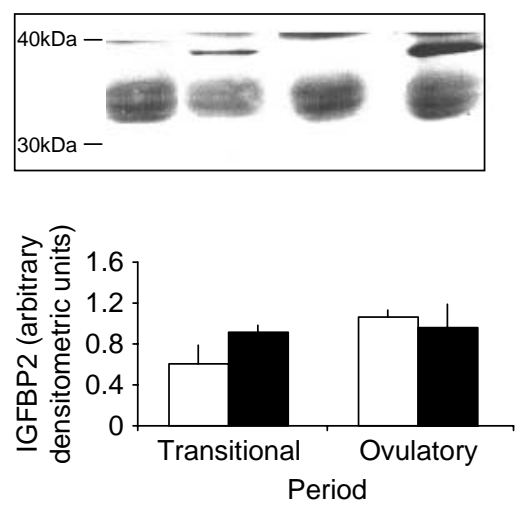

(c)
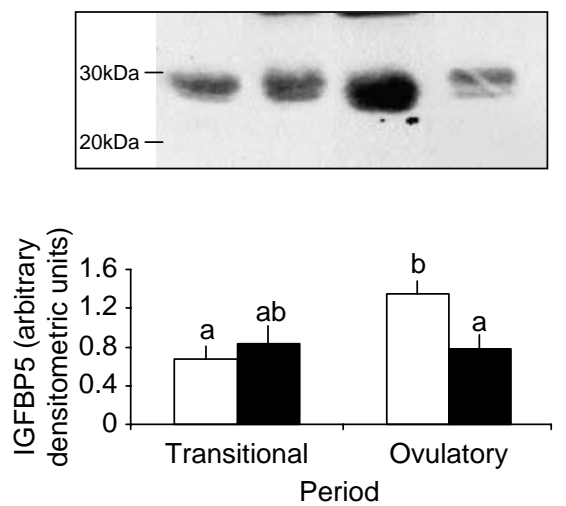

Figure 2 Relative follicular fluid levels (mean \pm s.E.M.) of (a) free IGF1, (b) IGFBP2 and (c) IGFBP5 in mares ( $n=5-6 /$ group) $24 \mathrm{~h}$ after injection of vehicle (white bars) or $10 \mu \mathrm{g}$ IGF1 (black bars) into the largest follicle of a wave during the transitional period or the second largest follicle during the ovulatory period. There was an effect of treatment for free IGF1 $(P=0.01)$. There were no main effects or an interaction for IGFBP2 $(P>0.1)$ but there was an interaction of period $\times$ treatment $(P=0.027)$ for IGFBP5. Means with different letters $(a, b)$ are different $(P<0.05)$. Representative immunoblots for each IGFBP are shown above the corresponding graph. during the ovulatory period than in IGF1-treated mares during the ovulatory period $(P<0.05)$ and vehicletreated mares during the transitional period $(P<0.05)$.

Follicular inhibin A concentrations (Fig. 3a) were affected by treatment $(P=0.01)$ but not by period or treatment $\times$ period $(P>0.1)$. Injection of IGF1 induced mean increases $(P=0.05)$ in inhibin A levels of 2.1- and 2.2 -fold during the transitional and ovulatory periods respectively.

Finally, although there was no overall effect $(P>0.4)$ of treatment or an interaction, oestradiol levels in follicular fluid were affected by period $(P=0.05)$ resulting in mean higher oestradiol levels (1.8-fold) during the ovulatory period than during the transitional period (Fig. 3b).

\section{Discussion}

This study used two complementary approaches in mares to investigate for the first time in vivo seasonal changes in follicular responses to IGF1, namely, 1) analyses of follicular IGF1R expression and IGFBP levels, both of which are major determinants of responsiveness to IGF1 and 2) quantification of actual follicle responses to intrafollicular injection of $10 \mu \mathrm{g}$ IGF1, as indicated by changes in follicular inhibin A and oestradiol levels. The use of the second largest follicle of an ovulatory wave as a reference to study the responses of transitional follicles is novel. Unlike the largest follicle of ovulatory waves (future dominant follicle), the second largest follicle is not exposed to an increase in follicular IGF1 at the beginning of deviation (Donadeu \& Ginther 2002b), which contributes to its inability to become ovulatory (Ginther et al. 2004b, 2004c). Transitional follicles develop in a similar IGF1-deficient environment after
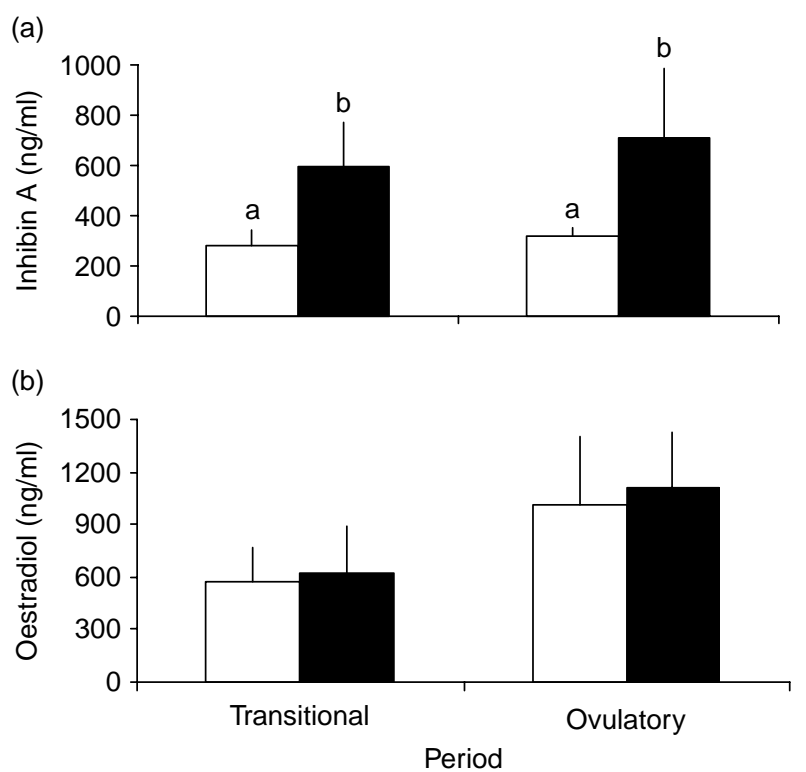

Figure 3 Mean ( \pm S.E.M.) follicular fluid concentrations of (a) inhibin A and (b) oestradiol in mares ( $n=5-7 /$ group) $24 \mathrm{~h}$ after injection of vehicle (white bars) or $10 \mu \mathrm{g}$ IGF1 (black bars) into the largest follicle of a wave during the transitional period or the second largest follicle during the ovulatory period. There were significant effects of treatment for inhibin $\mathrm{A}(P=0.01)$ and period for oestradiol $(P=0.05)$. Means within periods with different letters $(a, b)$ are different $(P<0.05)$. 
deviation resulting in the developmental deficiencies that prevent them from acquiring the ability to ovulate (Acosta et al. 2004, Watson et al. 2004a). The present study demonstrates that experimental comparisons between these two types of follicles can be useful to understand the biological mechanisms behind the anovulatory nature of transitional follicles and opens the way for the potential use of this comparative approach in future studies.

To our knowledge, changes in IGF receptor expression during follicular development have not previously been reported in the horse. IGF1R expression increased with follicle size during the ovulatory period but not during the transitional period, and this resulted in higher expression levels in $25-34 \mathrm{~mm}$ follicles during the ovulatory period than during the transitional period but similar levels in 15-24 mm follicles between the two periods. This result is consistent with the essential role of IGF1 in the selection and subsequent development of ovulatory follicles (reviewed in Beg \& Ginther 2006) and also with the causative role of deficient IGF1 stimulation in the failure of transitional follicles to develop characteristics of ovulatory follicles (reviewed in Donadeu \& Watson 2007). The present results in mares are in contrast to some of the previous studies in which IGF1R expression in granulosa cells did not change (Armstrong et al. 2000, Liu et al. 2000, Hastie \& Haresign 2006, Llewellyn et al. 2007) or decreased (Perks et al. 1995) during growth of antral follicles in cows and pigs or between seasons in sheep. Taken together, these results highlight species-specific differences in the pattern of IGF1R expression during follicle growth; however, it must also be recognised that quantification of mRNA levels in the present and previous studies may not adequately reflect the actual levels of functional IGF1R in follicles.

The expression levels of IGF2R, FSHR and LHCGR in granulosa cells were determined because the responses of follicular cells to IGF1 may depend, at least in part, on their concurrent responsiveness to IGF2 (Spicer \& Aad 2007) and gonadotrophins (Glister et al. 2001). IGF2 is naturally produced in equine follicular cells (Davidson et al. 2002, Watson et al. 2004a) and IGF2 expression is lower during the transitional period than during the ovulatory season (Watson et al. 2004a). IGF2 has been shown to promote bovine granulosa cell proliferation and steroidogenesis by binding to IGF1R (Spicer \& Aad 2007). In contrast, IGF2 binding to IGF2R results in the inactivation of IGF2 (Delaine et al. 2007). In this study, expression of IGF2R did not change significantly with follicle size but was higher during the transitional period than during the ovulatory period. Considering the role of IGF2R in regulating IGF2 bioavailability in the follicle, the present results suggest that the ability of IGF2 to activate IGF1R may be impaired in transitional follicles relative to ovulatory follicles. Although the effects of IGF1 injection on IGF2R were not determined in this study, IGF2R expression in bovine granulosa cells has been shown to decrease in response to IGF1 (Spicer \& Aad 2007).

The effects of season on follicular FSHR expression in horses have not been previously reported. In an earlier study, Fay \& Douglas (1987) failed to demonstrate changes in FSH binding to follicle walls during the oestrus cycle and those findings are consistent with the absence of significant changes in FSHR expression between follicles 15-24 and 25-34 mm during the ovulatory period in the present study. In contrast, FSHR expression decreased as transitional follicles grew above $24 \mathrm{~mm}$. The reason for this is not known but it does bring the possibility that a reduced responsiveness not only to $\mathrm{LH}$ but also to FSH may be involved in the failure of these follicles to acquire ovulatory capacity. The higher LHCGR expression in dominant-size follicles during the ovulatory period than during the transitional period is consistent with previous results (Watson et al. 2004b). Although not critically tested in the present study, reduced $L H C G R$ expression in transitional follicles is likely mediated, at least in part, by low levels of IGF1 in these follicles (Hirakawa et al. 1999). Overall, the results on receptor expression in this study indicated that follicles $15-24 \mathrm{~mm}$ have similar responsiveness to trophic stimuli, namely, IGF1, FSH and $\mathrm{LH}$, during transitional and ovulatory periods. Further analyses of IGF1 responsiveness of these follicles between periods were then performed by analysing follicular IGFBP levels and changes in inhibin $A$ and oestradiol in response to intrafollicular IGF1 administration.

There was no effect of period on intrafollicular levels of free IGF1 and this is consistent with results indicating that differences in intrafollicular levels of free IGF1 between transitional and ovulatory waves do not occur before the beginning of deviation (Acosta et al. 2004, Donadeu 2006). During the two periods, mean follicular levels of free IGF1 in mares injected with IGF1 or vehicle were lower than those reported in some of the previous equine studies (Donadeu \& Ginther 2002a, 2002b, Ginther et al. 2004a) but were comparable with natural levels in dominant and largest subordinate follicles respectively, at the beginning of deviation during ovulatory waves in another study (Ginther et al. 2005). The magnitude of the increase in intrafollicular free IGF1 after injection of $10 \mu \mathrm{g}$ IGF1 (average over the periods, 23.2-fold over saline-treated follicles) was consistent with results of previous IGF1 injection studies in ovulatory mares (Ginther et al. 2004c, 2005).

In the present study, vehicle-treated follicles were used to assess seasonal differences in the levels of IGFBP2 and IGFBP5, both of which critically contribute to the differential increase in IGF1 availability to the dominant follicle in ovulatory mares (Gerard \& Monget 1998, Bridges et al. 2002, Donadeu \& Ginther 2002b). The follicular puncture procedure used in this study has by 
itself no detectable effects on levels of follicular factors, including IGFBPs (Ginther et al. 2004c). Follicular IGFBP2 levels were similar between the transitional period (mean diameter of the largest follicle at the time of sampling, $19.5 \mathrm{~mm}$ ) and the ovulatory period (mean diameter of the second largest follicle, $18.8 \mathrm{~mm}$ ). In agreement with the present results, IGFBP2 levels were not different between $13 \mathrm{~mm}$ follicles collected during the transitional period and the ovulatory season (Donadeu 2006). In contrast, large follicles $(>30 \mathrm{~mm}$ ) had relatively higher IGFBP2 levels during the transitional period (Watson et al. 2004a). Taken together, these findings suggest that, in contrast to the ovulatory season (Gerard \& Monget 1998, Bridges et al. 2002), a decrease in follicular IGFBP2 levels in dominant follicles does not occur during the transitional period. A tendency for greater mean expression levels of PAPPA, an IGFBP protease (Gerard et al. 2004), in follicles 25-34 mm than in follicles $15-24 \mathrm{~mm}$ during the ovulatory period but not during the transitional period in this study are consistent with that conclusion. The lack of an effect of IGF1 injection on follicular IGFBP2 levels is in agreement with results by Ginther et al. (2004c, 2005) who showed that a much higher dose of IGF1 than the one used in the present study is needed to induce any detectable changes in follicular levels of IGFBP2.

The effects of season or IGF1 on follicular IGFBP5 levels in mares have not been reported before. The reason for higher levels of IGFBP5 during the ovulatory period (second largest follicle) than during the transitional period (largest follicle) in vehicle-treated mares is unknown. IGFBP5 levels (as well as levels of IGFBP2 and IGFBP4) have been shown to increase in subordinate follicles of ovulatory mares (Gerard \& Monget 1998, Donadeu \& Ginther 2002b). Based on results in cattle and horses, changes in follicular fluid levels of IGFBP5 and IGFBP4 during follicular waves seem to occur before the beginning of diameter deviation (reviewed in Beg \& Ginther 2006). In contrast, changes in follicular IGFBP2 levels are only detectable after deviation. Therefore, it is conceivable that in the present study, IGFBP5 levels (but not IGFBP2 levels) in the target follicle of the ovulatory period (second largest follicle) were already increasing when follicular fluid was collected for analyses. Another observation in the present study was that IGFBP5 levels were lower in IGF1- than vehicle-injected follicles during the ovulatory period. Follicular levels of IGF1 and IGFBP5 are negatively correlated during follicular growth in mares (Bridges et al. 2002). Considering that, together with the apparent early involvement of IGFBP5, compared with IGFBP2, during follicle selection (Beg \& Ginther 2006), it is plausible that in the present study IGFBP5 levels in the second largest follicle during the ovulatory period decreased in response to exogenous IGF1, a possibility that warrants further testing. Overall, these results on IGFBPs suggest that follicular IGFBP activity may be comparable during the transitional and ovulatory periods (based on IGFBP2 levels) or lower during the transitional period (based on IGFBP5). Although the relative contribution of IGFBP2 and IGFBP5 to regulation of follicular IGF1 activity in mares has not been directly determined, previous results using western ligand blotting suggest that follicular IGFBP2 is predominant over IGFBP4 and IGFBP5 during both the ovulatory and transitional periods (Gerard \& Monget 1998, Watson et al. 2004a). Considering this, overall IGFBP activity within follicles before the beginning of deviation is likely to be similar during transitional waves and ovulatory waves and this is consistent with similar levels of free IGF1 after IGF1 injection during the two periods in this study.

Inhibin A levels have been consistently shown to increase after IGF1 injection into the second largest follicle of ovulatory waves (Ginther et al. 2004c, 2005) as well as in the largest follicle during natural follicle selection (Donadeu \& Ginther 2002b). The mean increase in intrafollicular inhibin A induced by $10 \mu \mathrm{g}$ IGF1 during the ovulatory period (about twofold relative to vehicle-treated controls) was comparable with the increase reported after IGF1 injection into the second largest follicle in a previous study (Ginther et al. 2004c). More importantly, the inhibin A responses were similar during transitional and ovulatory periods and this was consistent with the absence of detectable differences in expression of IGF1R and follicular levels of IGFBP2 before the beginning of deviation between the two periods.

The differences in follicular oestradiol levels between periods in the present study indicate that deficient follicular steroidogenesis during transition is not limited to late dominant follicles (Davis \& Sharp 1991, Watson et al. 2002, 2004b) but it apparently also involves follicles before the beginning of deviation. Since IGF1 is known to stimulate steroidogenesis in vitro (Glister et al. 2001) and there is a temporal association between reduced IGF1 activity and low oestradiol levels during transition (reviewed in Donadeu \& Watson 2007), we wished to examine whether experimentally increasing intrafollicular IGF1 activity before the beginning of deviation during the transitional period would lead to an stimulation of oestradiol production. The absence of an oestradiol response to IGF1 in that regard is similar to results after intrafollicular IGF1 injection before the beginning of deviation in ovulatory mares (Ginther et al. $2004 c$, 2005) and is consistent with results in vitro showing that the ability of granulosa cells to respond with an increase in oestradiol may depend on the size of the follicles (Davidson et al. 2002). The present result indicates that, as during the ovulatory season, IGF1 may not acutely regulate oestradiol during the transitional period. It is also possible that a higher dose of IGF1 than the one used in this study was necessary to adequately stimulate not only granulosa cells but also theca cells, which is likely required to efficiently stimulate the 
natural increase in follicular production of oestradiol at the end of the transitional period (Watson et al. 2004b). Nonetheless, the present results together with those of previous studies (Donadeu \& Watson 2007) strongly suggest that the distinct increase in production of oestradiol by dominant follicles at the end of the transitional period involves not only an increase in IGF1 bioactivity but also an increase in the responsiveness of follicles to IGF1 and gonadotrophins (and likely other trophic factors).

In summary, expression of IGF1R, as well as FSHR and LHCGR, in granulosa cells from follicles 15-24 mm was similar during the transitional period and the ovulatory period, whereas expression of each of these receptors in follicles $25-34 \mathrm{~mm}$ was lower during the transitional period. IGF2R expression tended to be higher during the transitional period than during the ovulatory period, regardless of follicle diameter. In addition, follicular levels of IGFBP2 before the beginning of deviation were similar during the two periods whereas levels of IGFBP5 were lower during the transitional period. Injection of IGF1 into the largest follicle of a transitional wave before the beginning of deviation induced a approximately twofold mean increase in follicular inhibin A levels, similar to that induced after IGF1 injection into the second largest follicle of a wave during the ovulatory period. Finally, follicular oestradiol levels did not respond to IGF1 during any of the two periods. Taken together, these results indicate that follicular responsiveness to IGF1 before the beginning of deviation is comparable during transitional waves and ovulatory waves and, therefore, this is likely not a primary cause of the deficient development of dominant follicles during transition.

\section{Materials and Methods}

\section{Animals and experimental design}

Eight horse mares of mixed breeding, aged 4-16 years, body weight $400-600 \mathrm{~kg}$, were kept under natural light in an open shelter and outdoor paddock in the northern hemisphere $\left(55^{\circ} \mathrm{N}\right.$; Edinburgh, UK). Mares were fed alfalfa/grass hay and had free access to water and mineralised salt. All experimental procedures were carried out under the UK Home Office Animals (Scientific Procedures) Act 1986, after approval by the Ethical Review Committee, University of Edinburgh.

Beginning in February, each of the eight mares was used during two different reproductive periods, transitional (February to April) and ovulatory (June to August). Within each period, a cross-over design was used whereby each of these mares was randomly assigned once to each of two treatments, IGF1 and vehicle, leaving a $\geq 30$-day rest between the two treatments. Therefore, the same mares were used within each treatment during the two periods. At the beginning of the transitional period, mares had at least one follicle $>20 \mathrm{~mm}$ and no detectable corpus luteum for the previous 4 weeks; these criteria excluded animals that were in deep anoestrus or ovulatory respectively.

\section{Follicle ablation, treatments and sample collection}

Before each treatment during both periods, all follicles $>10 \mathrm{~mm}$ were ablated by ultrasound-guided transvaginal aspiration of follicular contents, as described (Gastal et al. 1997), using a 17 gauge, $55 \mathrm{~cm}$ ovum pickup needle (Popper \& sons, Inc., New Hyde Park, NY, USA) attached to a $5 \mathrm{MHz}$ curved array transducer on an Aloka $500 \mathrm{~V}$ ultrasound scanner (BCF Technology, Livingston, UK). This was done to eliminate follicles from previous waves and provide a uniform follicle status before the treatments across periods. During the ovulatory period, follicle ablations were always performed during mid-cycle (10-15 days after ovulation). In both periods, aspirates from follicles 15-24 and 25-34 mm were collected and separately pooled within each mare. These two diameter categories correspond to follicles before and after the beginning of diameter deviation during a follicular wave (Donadeu \& Ginther 2004). Follicle aspirates were centrifuged at $2000 \mathrm{~g}$ at $4{ }^{\circ} \mathrm{C}$ for $5 \mathrm{~min}$ and Trizol reagent was added to the granulosa cell pellets before they were frozen at $-80{ }^{\circ} \mathrm{C}$ for subsequent RNA extraction and gene expression analyses. Cell pellets with gross blood contamination were discarded.

Following ablation of all follicles $>10 \mathrm{~mm}$, the ovaries were monitored daily with the same scanner equipped with a $5 \mathrm{MHz}$ linear-array transducer (BCF Technology). At each scanning session, the diameter of follicles $10-15 \mathrm{~mm}$ was estimated by comparison with the graduation marks on the scanner screen and follicles $>15 \mathrm{~mm}$ were measured with the electronic callipers. Follicles were measured in two planes and the average of length and width from a frozen image was taken as the actual diameter. Follicles that refilled with fluid to $>15 \mathrm{~mm}$ were re-ablated.

During the transitional period, once the largest follicle of the post-ablation wave reached $\geq 18 \mathrm{~mm}$, corresponding to about 1 day before the expected beginning of deviation (Donadeu \& Ginther 2004), the follicle was injected with $10 \mu \mathrm{g}$ recombinant human IGF1 (NHPP, Torrance, CA, USA) in a $100 \mu$ l citrate buffer or with $100 \mu \mathrm{l}$ citrate buffer vehicle. The dose of IGF1 was chosen based on the results of a previous dose-response study in ovulatory mares (Ginther et al. 2004c); this dose was intermediate between two doses (2.5 and $25 \mu \mathrm{g})$ that when injected into subordinate follicles induced responses over a 48-h period that were similar to those naturally occurring in dominant follicles. Injection was done by ultrasound-guided transvaginal follicular puncture using an outer $20 \mathrm{~g}$ needle to penetrate the ovarian stroma and an inner 25 g needle to enter the follicle, as described (Gastal et al. 1995). During the ovulatory period, the second largest follicle of the post-ablation wave was injected once the largest follicle reached $\geq 21 \mathrm{~mm}$, which corresponded to an expected mean diameter for the target follicle (second largest follicle) of $18 \mathrm{~mm}$ (Donadeu \& Ginther 2004), comparable with the diameter of target follicles during the transitional period. During both the transitional period and the ovulatory period, follicular contents were aspirated from the target follicles $24 \mathrm{~h}$ after injection, followed by centrifugation and storage of the resulting supernatant at $-20{ }^{\circ} \mathrm{C}$. Follicular aspirates grossly contaminated with blood were discarded ( $n=2$ samples). Mares were scanned twice a week between treatments and the presence of a corpus luteum was used to indicate that ovulation had occurred. 


\section{Quantification of gene expression by $q P C R$}

Total RNA from pooled granulosa cell samples was isolated using the guanidium isothiocyanate-phenol-chloroform method (Chomczynski \& Sacchi 1987) and reverse transcribed using Superscript III (Invitrogen) and random primers $\left(\mathrm{p}(\mathrm{dN})_{6}\right.$; Promega). The cDNA product was quantified using the SYBR GreenER qPCR SuperMix Universal Kit (Invitrogen) for amplicon detection and ROX as an internal reference dye in a DNA Engine Opticon 2 (MJ Research Inc., Waltham, MA, USA). Primers (Table 1) were designed based on available equine sequences or, in the case of IGF1R, based on conserved sequences in bovine, porcine and murine. Primers were designed to span two different exons within the corresponding genomic sequence and their specificity was confirmed by ensuring each product yielded the expected length on an agarose gel. PCR settings used were for all genes analysed $50{ }^{\circ} \mathrm{C}$ for $2 \mathrm{~min}, 95^{\circ} \mathrm{C}$ for $10 \mathrm{~min}$, and 40 cycles of $95^{\circ} \mathrm{C}$ for $15 \mathrm{~s}$, $57^{\circ} \mathrm{C}\left(I G F 1 R, I G F 2 R\right.$ and PAPPA) or $52^{\circ} \mathrm{C}$ (FSHR, LHCGR and $18 S R N A)$ for $30 \mathrm{~s}$ and $72{ }^{\circ} \mathrm{C}$ for $45 \mathrm{~s}$. The abundance of each target mRNA was calculated with Mx3000P real-time PCR system analysis software (Stratagene, La Jolla, CA, USA) relative to a standard curve constructed from granulosa cells pooled from equine follicles of different sizes. 18S RNA was used as internal control for each of the genes analysed. Melting curves for each sample were examined to further confirm the specificity of the qPCR product. Intra-assay coefficients of variation (CV) for all genes analysed were between 0.95 and $3.44 \%$.

\section{IGFBP immunoblotting}

Follicular fluid was assayed for protein content using the DC protein assay kit (Bio-Rad). Forty micrograms of protein (corresponding to $6-8 \mu \mathrm{l}$ of a 1:10 dilution of follicular fluid) were heat-denatured in buffer containing $12 \%$ SDS, $40 \%$ glycerol, $30 \% \quad \beta$-mercaptoethanol, $300 \mathrm{mM}$ dithiothreitol, $120 \mathrm{mM}$ EDTA, $1 \mathrm{mg} / \mathrm{ml}$ bromophenol blue and $375 \mathrm{mM}$ Tris$\mathrm{HCl}$ (pH 6.8) before being resolved on a $12 \%$ polyacrylamide gel. This was followed by electroblotting onto PVDF membranes for $1 \mathrm{~h}$ at room temperature. Membranes were then blocked for $2 \mathrm{~h}$ in a solution $(10 \mathrm{mM}$ Tris, $100 \mathrm{mM} \mathrm{NaCl}, 0.2 \%$ Tween 20) containing 5\% BSA and incubated overnight with anti-bovine IGFBP2 (1:1000; 06-107, Upstate, Hampshire, UK) or antihuman IGFBP5 (1:1000; 06-110, Upstate). Membranes were incubated with HRP-conjugated anti-rabbit anti-immunoglobulin (1:10 000; Amersham Biosciences) for $1 \mathrm{~h}$. After further washing, immune complexes were visualised and quantified using the Super Signal West Femto maximum sensitivity detection system (Pierce Chemical Inc., Rockford, IL, USA) and imaged using Fluro-S Scanning System (Bio-Rad Laboratories Ltd). Densitometry analyses were done using Quantity One Analysis Software (Bio-Rad).

\section{Free IGF1, inhibin A and oestradiol immunoassays}

Concentrations of free IGF1 were quantified by a sandwichtype ELISA (Diagnostic Systems Laboratories, Webster, TX, USA) adapted for use with mare follicular fluid (Donadeu \& Ginther 2002b). The samples were used undiluted. Anti-sera cross-reactivity with IGF2, insulin or IGFBPs was not found by the manufacturer. Intra-assay $\mathrm{CV}$ was $6.5 \%$ and assay sensitivity was $25.0 \mathrm{pg} / \mathrm{ml}$. For all assays, sensitivity was considered as 2 standard deviations above the mean optical density (OD) of the zero standard corrected for sample dilution.

Concentrations of inhibin $A$ in the follicular fluid were determined with a sandwich ELISA kit (Diagnostic Systems Laboratories). The kit was developed for use with human samples and was adapted and validated for use with equine follicular fluid in our laboratory. Serial dilutions (1:100 to 1:100 000) of a pool of equine follicular fluid in the provided assay diluent resulted in a displacement curve that was parallel to the standard curve provided (0-1 ng/ml). A working dilution of 1:1000 was used for assaying the follicular fluid samples. This was chosen based on the dilution of pooled follicular fluid that resulted in an OD that was central to the range of the standard curve. According to the manufacturer, there was no significant cross-reactivity of the assay with inhibin B, pro- $\alpha \mathrm{C}$ inhibin, or activin-A and $-\mathrm{B}$. The intra-assay CV was $6.7 \%$ and the sensitivity was $19.7 \mathrm{ng} / \mathrm{ml}$.

Oestradiol levels in follicular fluid were measured by RIA as described (England et al. 1981) without previous extraction of samples. The intra-assay CV was $9.6 \%$ and the sensitivity was $5.0 \mathrm{pg} / \mathrm{ml}$.

\section{Statistical analyses}

Dixon's Q-test was used to identify outliers using $P<0.05$ as a cut-off value to exclude a sample from subsequent analysis.

Table 1 Primer sequences used in qPCR analyses of equine granulosa cells.

\begin{tabular}{|c|c|c|c|}
\hline Target & Accession number & Sequences & Product (bp) \\
\hline$I G F 1 R$ & X54980.1 & $\begin{array}{l}\text { For 5'-AAGCTGAGAAGCAGGCAGAG-3' } \\
\text { Rev 5'-CGGAGGTTGGAGATGACAGT-3' }\end{array}$ & 265 \\
\hline$I G F 2 R$ & XM_001491469 & $\begin{array}{l}\text { For 5'-GTAACGCTAAGCTTTCCTATT ACG-3' } \\
\text { Rev 5'-GGTATACCACCGGAAGTTGTA GG-3' }\end{array}$ & 187 \\
\hline$F S H R^{\mathrm{a}}$ & S70150 & $\begin{array}{l}\text { For 5'-TCTTTGGCATCAGCACCTAC-3' } \\
\text { Rev 5'-AGAAATCCCTGCGGAAGTTC-3' }\end{array}$ & 399 \\
\hline$L H C G R$ & AY464091 & $\begin{array}{l}\text { For 5'-CCCGGTTAAAATACCTAAGC-3' } \\
\text { Rev 5'-AGTGTCGTCCCGTTGAA-3 }{ }^{\prime}\end{array}$ & 229 \\
\hline PAPPA & XM_001487931 & $\begin{array}{l}\text { For 5'-TCACGCCCAATCAAGT-3' } \\
\text { Rev 5'-AGGTCACATGCTGATCC-3' }\end{array}$ & 196 \\
\hline $18 S R N A$ & AJ311673 & $\begin{array}{l}\text { For 5'-GGGGAATCAGGGTTCG-3' } \\
\text { Rev 5'-GCTGGCACCAGACTTG-3 } 3^{\prime}\end{array}$ & 209 \\
\hline
\end{tabular}

aPrimer sequences from Dell'Aquila et al. (2004). 
Data for each end point were log-transformed before analyses whenever a Kolmogorov-Smirnoff test (significance level $=0.01$ ) indicated lack of normality. For all end points, main effects (period, follicle size and/or treatment) and their interactions were analyzed with the General Linear Model (Minitab 15) using a split-plot design with mare as block. To rule out any carry-over effect derived from the repeated use of mares within each period, an additional main effect included in the analyses was whether a treatment was first or second during a period. When a main effect was significant or approached significance, Tukey's test was used to locate differences between means. A probability of $<0.05$ indicated that a difference was significant and probabilities between $>0.05$ and $<0.1$ indicated a difference approaching significance.

\section{Declaration of interest}

There is no conflict of interest that could be perceived as prejudicing the impartiality of this study.

\section{Funding}

This study was supported by a Royal (Dick) School of Veterinary Studies scholarship to L K Doyle (E06008).

\section{Acknowledgements}

The authors thank Erin Morgan for assistance with qPCR and Graeme Milne for animal handling.

\section{References}

Acosta TJ, Beg MA \& Ginther OJ 2004 Aberrant blood flow area and plasma gonadotropin concentrations during the development of dominant-sized transitional anovulatory follicles in mares. Biology of Reproduction $\mathbf{7 1}$ 637-642.

Armstrong DG, Gutierrez CG, Baxter G, Glazyrin AL, Mann GE, Woad KJ, Hogg CO \& Webb R 2000 Expression of mRNA encoding IGF-I, IGF-II and type 1 IGF receptor in bovine ovarian follicles. Journal of Endocrinology 165 101-113.

Beg MA \& Ginther OJ 2006 Follicle selection in cattle and horses: role of intrafollicular factors. Reproduction 132 365-377.

Bridges TS, Davidson TR, Chamberlain CS, Geisert RD \& Spicer LJ 2002 Changes in follicular fluid steroids, insulin-like growth factors (IGF) and IGF-binding protein concentration, and proteolytic activity during equine follicular development. Journal of Animal Science $\mathbf{8 0}$ 179-190.

Chomczynski P \& Sacchi N 1987 Single-step method of RNA isolation by acid guanidinium thiocyanate-phenol-chloroform extraction. Analytical Biochemistry 162 156-159.

Davidson TR, Chamberlain CS, Bridges TS \& Spicer LJ 2002 Effect of follicle size on in vitro production of steroids and insulin-like growth factor (IGF)-I, IGF-II, and the IGF-binding proteins by equine ovarian granulosa cells. Biology of Reproduction 66 1640-1648.

Davis SD \& Sharp DC 1991 Intra-follicular and peripheral steroid characteristics during vernal transition in the pony mare. Journal of Reproduction and Fertility 44 333-340.

Delaine C, Alvino CL, McNeil KA, Mulhern TD, Gauguin L, De Meyts P, Jones EY, Brown J, Wallace JC \& Forbes BE 2007 A novel binding site for the human insulin-like growth factor-II (IGF-II)/mannose 6-phosphate receptor on IGF-II. Journal of Biological Chemistry 282 18886-18894.

Dell 'Aquila ME, Caillaud M, Maritato F, Martoriati A, Gérard N, Aiudi G, Minoia P \& Goudet G 2004 Cumulus expansion, nuclear maturation and connexin 43, cyclooxygenase-2 and FSH receptor mRNA expression in equine cumulus-oocyte complexes cultured in vitro in the presence of FSH and precursors for hyaluronic acid synthesis. Reproductive Biology and Endocrinology 2244.

Donadeu FX 2006 Early indicators of follicular growth during the anovulatory season in mares. Animal Reproduction Science 94 179-181.

Donadeu FX \& Ginther OJ 2002a Follicular waves and circulating concentrations of gonadotrophins, inhibin and oestradiol during the anovulatory season in mares. Reproduction 124 875-885.

Donadeu FX \& Ginther OJ $2002 b$ Changes in concentrations of follicular fluid factors during follicle selection in mares. Biology of Reproduction 66 1111-1118.

Donadeu FX \& Ginther OJ 2003 Interactions of follicular factors and season in the regulation of circulating concentrations of gonadotrophins in mares. Reproduction 125 743-750.

Donadeu FX \& Ginther OJ 2004 Interrelationships of estradiol, inhibin, and gonadotropins during follicle deviation in pony mares. Theriogenology 61 1395-1405.

Donadeu FX \& Watson ED 2007 Seasonal changes in ovarian activity: lessons learnt from the horse. Animal Reproduction Science $\mathbf{1 0 0}$ 225-242.

England BG, Dahmer MK \& Webb R 1981 Relationships between follicular size and antral fluid steroid concentrations at three stages of the estrous cycle in the ewe. Biology of Reproduction 24 1068-1075.

Fay JE \& Douglas RH 1987 Changes in thecal and granulosa cell LH and FSH receptor content associated with follicular fluid and peripheral plasma gonadotrophin and steroid hormone concentrations in preovulatory follicles of mares. Journal of Reproduction and Fertility Supplement 35 169-181.

Gastal EL, Kot K \& Ginther OJ 1995 Ultrasound-guided intrafollicular treatment in mares. Theriogenology 44 1027-1037.

Gastal EL, Gastal MO, Bergfelt DR \& Ginther OJ 1997 Role of diameter differences among follicles in selection of a future dominant follicle in mares. Biology of Reproduction 57 1320-1327.

Gerard N \& Monget P 1998 Intrafollicular insulin-like growth factorbinding protein levels in equine ovarian follicles during preovulatory maturation and regression. Biology of Reproduction 58 1508-1514.

Gerard N, Delpuech T, Oxvig C, Overgaard MT \& Monget P 2004 Proteolytic degradation of IGF-binding protein (IGFBP)-2 in equine ovarian follicles: involvement of pregnancy-associated plasma protein-A (PAPP-A) and association with dominant but not subordinated follicles. Journal of Endocrinology 182 457-466.

Ginther OJ, Woods BG, Meira C, Beg MA \& Bergfelt DR 2003 Hormonal mechanism of follicle deviation as indicated by major versus minor follicular waves during the transition into the anovulatory season in mares. Reproduction 126 653-660.

Ginther OJ, Gastal EL, Gastal MO \& Beg MA 2004a Critical role of insulinlike growth factor system in follicle selection and dominance in mares. Biology of Reproduction 70 1374-1379.

Ginther OJ, Bergfelt DR, Beg MA, Meira C \& Kot K $2004 b$ In vivo effects of an intrafollicular injection of insulin-like growth factor 1 on the mechanism of follicle deviation in heifers and mares. Biology of Reproduction 70 99-105.

Ginther OJ, Gastal EL, Gastal MO, Checura CM \& Beg MA 2004c Doseresponse study of intrafollicular injection of insulin-like growth factor-I on follicular fluid factors and follicle dominance in mares. Biology of Reproduction 70 1063-1069.

Ginther OJ, Gastal EL, Gastal MO \& Beg MA 2005 In vivo effects of pregnancy-associated plasma protein-A, activin-A and vascular endothelial growth factor on other follicular-fluid factors during follicle deviation in mares. Reproduction 129 489-496.

Glister C, Tannetta DS, Groome NP \& Knight PG 2001 Interactions between follicle-stimulating hormone and growth factors in modulating secretion of steroids and inhibin-related peptides by nonluteinized bovine granulosa cells. Biology of Reproduction 65 1020-1028.

Hastie PM \& Haresign W 2006 Expression of mRNAs encoding insulin-like growth factor (IGF) ligands, IGF receptors and IGF binding proteins during follicular growth and atresia in the ovine ovary throughout the oestrous cycle. Animal Reproduction Science 92 284-299.

Hirakawa T, Minegishi T, Abe K, Kishi H, Ibuki Y \& Miyamoto K 1999 A role of insulin-like growth factor I in luteinizing hormone receptor expression in granulosa cells. Endocrinology 140 4965-4971. 
King SS, Jones KL, Mullenix BA \& Heath DT 2008 Seasonal relationships between dopamine D1 and D2 receptor and equine FSH receptor mRNA in equine ovarian epithelium. Animal Reproduction Science 108 259-266.

Liu J, Koenigsfeld AT, Cantley TC, Boyd CK, Kobayashi Y \& Lucy MC 2000 Growth and the initiation of steroidogenesis in porcine follicles are associated with unique patterns of gene expression for individual componentsof the ovarian insulin-like growth factor system. Biology of Reproduction 63 942-952.

Llewellyn S, Fitzpatrick R, Kenny DA, Murphy J, Scaramuzzi RJ \& Wathes DC 2007 Effect of negative energy balance on the insulin-like growth factor system in pre-recruitment ovarian follicles of post partum dairy cows. Reproduction 133 627-639.

Mazerbourg S, Bondy CA, Zhou J \& Monget P 2003 The insulin-like growth factor system: a key determinant role in the growth and selection of ovarian follicles? A Comparative Species Study. Reproduction in Domestic Animals 38 247-258.

Perks CM, Denning-Kendall PA, Gilmour RS \& Wathes DC 1995 Localization of messenger ribonucleic acids for insulin-like growth factor I (IGF-I), IGF-II, and the type 1 IGF receptor in the ovine ovary throughout the estrous cycle. Endocrinology 136 5266-5273.

Sharp DC, Grubaugh WR, Weithenauer J, Davis SD \& Wilcox CJ 1991 Effects of steroid administration on pituitary luteinizing hormone and follicle-stimulating hormone in ovariectomized pony mares in the early spring: pituitary responsiveness to gonadotropin-releasing hormone and pituitary gonadotropin content. Biology of Reproduction 44 983-990.

Sharp DC, Wolfe MW, Cleaver BD \& Nilson J 2001 Effects of estradiol17 beta administration on steady-state messenger ribonucleic acid (MRNA) encoding equine alpha and LH/CGbeta subunits in pituitaries of ovariectomized pony mares. Theriogenology 55 1083-1093.

Spicer LJ \& Aad PY 2007 Insulin-like growth factor (IGF) 2 stimulates steroidogenesis and mitosis of bovine granulosa cells through the IGF1 receptor: role of follicle-stimulating hormone and IGF2 receptor. Biology of Reproduction 77 18-27.
Spicer LJ, Santiago CA, Davidson TR, Bridges TS \& Chamberlain CS 2005 Follicular fluid concentrations of free insulin-like growth factor (IGF)-I during follicular development in mares. Domestic Animal Endocrinology 29 573-581.

Stewart RE, Spicer LJ, Hamilton TD, Keefer BE, Dawson LJ, Morgan GL \& Echternkamp SE 1996 Levels of insulin-like growth factor (IGF) binding proteins, luteinizing hormone and IGF-I receptors, and steroids in dominant follicles during the first follicular wave in cattle exhibiting regular estrous cycles. Endocrinology 137 2842-2850.

Watson ED \& Al-zi'abi MO 2002 Characterization of morphology and angiogenesis in follicles of mares during spring transition and the breeding season. Reproduction 124 227-234.

Watson ED, Thomassen R, Steele M, Heald M, Leask R, Groome NP \& Riley SC 2002 Concentrations of inhibin, progesterone and oestradiol in fluid from dominant and subordinate follicles from mares during spring transition and the breeding season. Animal Reproduction Science $\mathbf{7 4}$ 55-67.

Watson ED, Bae SE, Thomassen R, Thomson SR, Woad K \& Armstrong DG 2004 Insulin-like growth factors-I and -II and insulin-like growth factorbinding protein-2 in dominant equine follicles during spring transition and the ovulatory season. Reproduction 128 321-329.

Watson ED, Bae SE, Steele M, Thomassen R, Pedersen HG, Bramley T, Hogg CO \& Armstrong DG 2004b Expression of messenger ribonucleic acid encoding for steroidogenic acute regulatory protein and enzymes, and luteinizing hormone receptor during the spring transitional season in equine follicles. Domestic Animal Endocrinology 26 215-230.

Received 13 November 2007

First decision 7 January 2008

Revised manuscript received 31 July 2008

Accepted 6 August 2008 